\title{
Distribution and temporal trends of butyltins monitored by molluscs along the Chinese Bohai coast from 2002 to 2005
}

\author{
Ruiqiang Yang, Dandan Cao, Qunfang Zhou, Yawei Wang, Guibin Jiang * \\ State Key Laboratory of Environmental Chemistry and Ecotoxicology, Research Center for Eco-Environmental Sciences, \\ Chinese Academy of Sciences, P.O. Box 2871, Beijing, 100085, China \\ Received 30 September 2007; accepted 23 January 2008 \\ Available online 4 March 2008
}

\begin{abstract}
Thirteen areas around the Chinese Bohai coast, individuals including ten kinds of bivalves and two kinds of snails were collected during the period of 2002-2005 for the investigation of spatial distribution and temporal variations of butyltin compounds (BTs). BTs including tributyltin (TBT) and its derivates, dibutyltin (DBT) and monobutyltin (MBT) were quantified by gas chromatography/flame photometric detection after extraction and Grignard derivatization. BTs compounds were widely existed in the samples and TBT was the dominant composition, indicating recent TBT input along Bohai coast. As a whole, BTs concentration remained high during the sampling years except a slightly decreased in samples from several sites in 2005. The contamination characteristics of BTs in different sampling sites were analyzed using principal component analysis (PCA) method, and the species specific bioaccumulation of BTs was also identified using cluster analysis.
\end{abstract}

(C) 2008 Elsevier Ltd. All rights reserved.

Keywords: Antifouling paints; Tributyltin (TBT); Organotins; Principal component analysis (PCA); Bivalve; Snail

\section{Introduction}

Tributyltin (TBT) has been used worldwide in antifouling paints for ships and fishing nets since the mid-1960s, and its derivatives dibutyltin (DBT) and monobutyltin (MBT) were mostly used as stabilizers in polyvinyl chloride and as catalysts in industrial processes (Fent, 1996). Aquatic pollution by butyltin compounds has been of great concern due to their severe impacts on non-target marine organisms such as shell malformation in oysters (Morcillo and Porte, 1998; Sidharthan et al., 2002) and imposex in gastropods (Michael, 2002; Konstantinou and Albanis, 2004). Accordingly, environmental concern led to the restriction of TBT-based antifouling paints on vessels under $25 \mathrm{~m}$ in many countries since 1980s (Champ, 2000). According to the resolution of International Maritime Organisation (IMO) meeting in October 2001, a global restriction has been implemented on the TBT-based antifouling paints on ships by January 1, 2003, and a complete prohibition

\footnotetext{
* Corresponding author. Tel.: +86 10 62849334; fax: +86 1062849179 .
}

E-mail address: gbjiang@rcees.ac.cn (G. Jiang). by January 1, 2008 (Rüdel et al., 2003). This proposal has yet received the majority support from the member countries to make it effect. However, the related legislative control on organotin is not reacted up to now in many Asian developing countries, including China. High concentrations of BTs in seawater, sediments, and biota samples have been detected in some Asian nations such as Thailand (Kan-atireklap et al., 1998), Malaysia (Tong et al., 1996), Korea (Shim et al., 2005), and Vietnam (Midorikawa et al., 2004). These studies indicated that the major source of TBT in the marine environment comes from the application in antifouling paints.

Our previous studies have revealed the severe and wide contamination of BTs in Chinese seafood (Zhou et al., 2001) and lake, river and coastal waters (Jiang et al., 2001). However, comprehensive and continuous monitoring data is still scarce, especially for such a special region of Bohai Sea, which located in the northeast of China with the heavy industries and the fishing culture relatively high developed. The semi-enclosed aquatic systems make the exchange of the seawater with the outer very slow. Therefore, serious environmental pollution might occur in the Bohai Sea. It is urgent and necessary to carry 


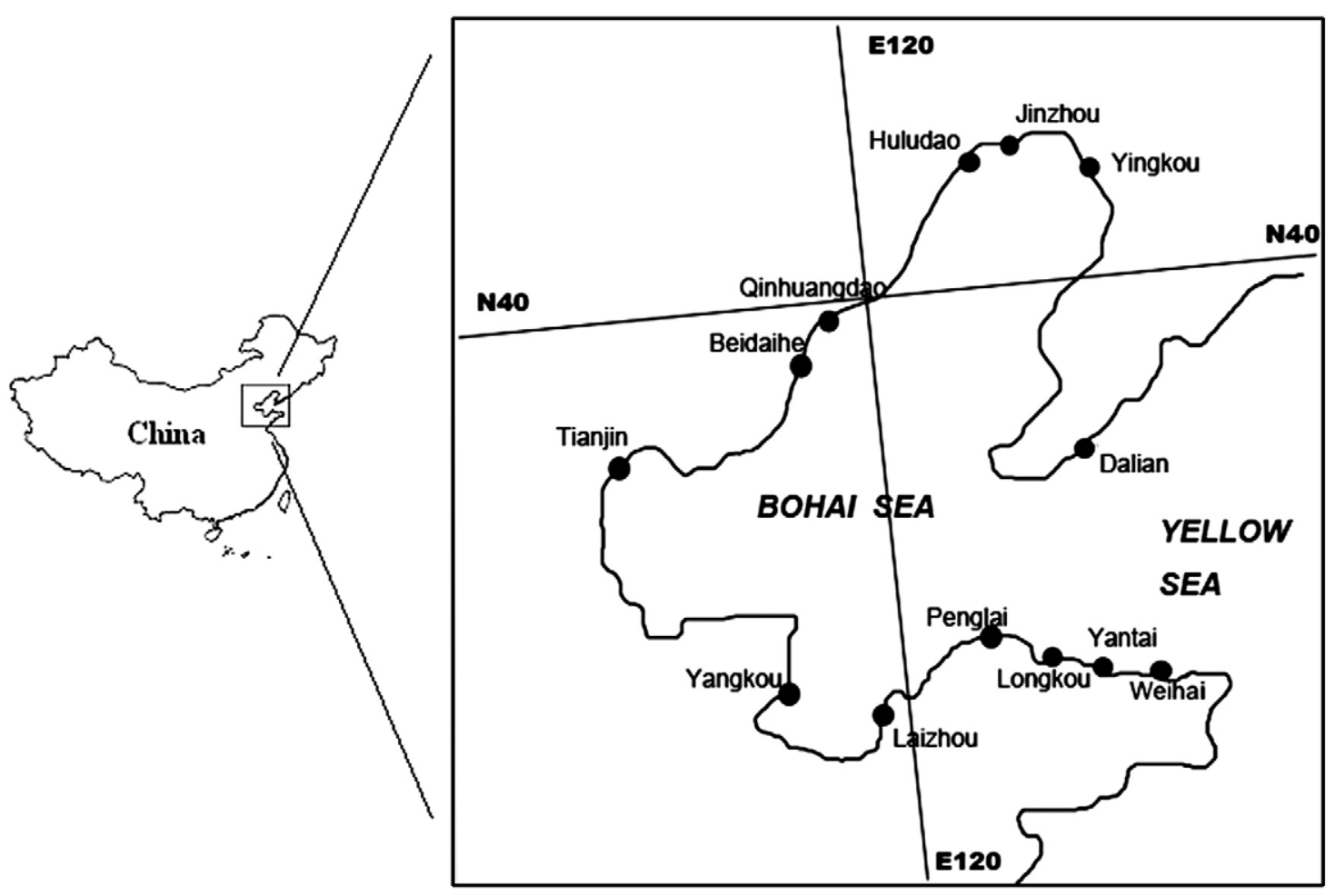

Fig. 1. Sampling locations of mollusc samples along the Chinese Bohai Sea.

out the widespread monitoring programme on BTs contamination in China to sketch the pollution status and trends of BTs.

Molluscs are good accumulators for persistent toxic substances in coastal waters and can be used as valuable biomonitors to reflect the aquatic pollution (Rainbow, 1995; Salánki et al., 2003). Organotin concentrations in biota are usually much higher than those in ambient water and reflecting time integrated information of exposure. Reported bioconcentration factors (BCF) for TBT in marine mussels (M. edulis) are between 5000 and 10,400 (Laughlin et al., 1986). In this work, altogether 427 mollusc samples including twelve different species were collected from thirteen typical coastal sites along the China Bohai Sea during four sampling campaigns from 2002 to 2005 . The present study aims to reveal exposure level of organism to BTs depending on sampling sites and temporal variations in coastal waters of China Bohai Sea.

Table 1

The denomination of the selected molluses

\begin{tabular}{llll}
\hline & Species & Abbreviation & Denomination \\
\hline Snail & Rapana venosa & Rap & Valenciennes, 1846 \\
& Neverita didyma & $\mathrm{Nev}$ & Röding, 1798 \\
& Scapharca subcrenata & $\mathrm{Sca}$ & Lischke, 1869 \\
& Mytilus edulis & $\mathrm{Myt}$ & Linnaeus, 1758 \\
& Ostrea talienwhanensis & $\mathrm{Ost}$ & Crosse, 1862 \\
& Amusium & $\mathrm{Amu}$ & Röding, 1798 \\
& Meretix meretrix & $\mathrm{Mer}$ & Linnaeus, 1758 \\
Bivalve & Ruditapes philippinarum & $\mathrm{Rud}$ & Adams and Reeve, 1850 \\
& Mactra veneriformis & Mac & Reeve, 1854 \\
& Chlamys farrer & $\mathrm{Chl}$ & Jones and Preston, 1904 \\
& Sinonovacula constricta & Sin & Lamarck, 1818 \\
& Mya arenaria & Mya & Linnaeus, 1758 \\
\hline
\end{tabular}

\section{Materials and methods}

\subsection{Sampling sites and sample preparation}

The coastal line of the Bohai Sea has a length of nearly $3800 \mathrm{~km}$. Fig. 1 shows the thirteen sampling sites around the Bohai Sea $\left(37^{\circ} 30^{\prime}-41^{\circ} 00^{\prime} \mathrm{N}\right.$ latitude, $117^{\circ} 30^{\prime}-121^{\circ} 30^{\prime} \mathrm{E}$ longitude). Most of the mollusc samples were collected from the large seaports where many ships and pleasure crafts traffic. These samples were recognized as commercially valuable seafood and are highly suitable culture in these coastal areas. As the reference sites, the samples of Yingkou were collected mostly from fishery areas, while those from Yangkou, a small port possessing of less density of ship activities.

The sampling was carried out four times during July-August, from 2002 to 2005. Mollusc samples include ten kinds of bivalves and two kinds of snails (Table 1). Different species were carefully identified according to the directory of marine molluscs in a reference book (Zhao et al., 1982). Samples were stored in an ice-cooled box during the transportation and then kept at $-20^{\circ} \mathrm{C}$ in the refrigerator in the laboratory. Before analysis, the shell of the organisms was removed, and the soft tissues were pooled and thoroughly rinsed with de-ionized water to wipe off extraneous impurities. After the sufficient homogenate by a stainless blender, the sub-samples were used for analysis.

Table 2

Results of the determination of butyltins in certified reference materials CRM 477

\begin{tabular}{|c|c|c|c|}
\hline \multirow[t]{2}{*}{ Compounds } & \multirow{2}{*}{$\begin{array}{l}\frac{\text { Determination value }}{\left(\text { mean }^{\mathrm{a}} \pm \text { S.D. }\right.}{ }^{\mathrm{b}}, \\
\left.\mu \mathrm{g} \mathrm{g}^{-1}\right)^{\mathrm{c}}\end{array}$} & \multirow{2}{*}{$\begin{array}{l}\frac{\text { Certified value }}{\left(\text { mean }^{\mathrm{a}} \pm \text { S.D. }\right.}{ }^{\mathrm{b}} \\
\left.\mu \mathrm{g} \mathrm{g}^{-1}\right)^{\mathrm{c}}\end{array}$} & \multirow{2}{*}{$\begin{array}{l}\text { Determination } \\
\text { error }(\%)\end{array}$} \\
\hline & & & \\
\hline MBT & $1.38 \pm 0.18$ & $1.50 \pm 0.28$ & -8 \\
\hline DBT & $1.48 \pm 0.15$ & $1.54 \pm 0.12$ & -5 \\
\hline TBT & $2.13 \pm 0.21$ & $2.20 \pm 0.19$ & -3 \\
\hline
\end{tabular}

a $N=3$.

b Standard deviation.

c The concentrations of BTs were expressed as cationic molecular weights, i.e., TBT: $\operatorname{Sn}\left(\mathrm{C}_{4} \mathrm{H}_{9}\right)_{3}^{+}, \mathrm{DBT}: \mathrm{Sn}\left(\mathrm{C}_{4} \mathrm{H}_{9}\right)_{2}^{+}$, MBT: $\mathrm{SnC}_{4} \mathrm{H}_{9}^{+}$. 


\subsection{Instrumental}

A GC-9A gas chromatograph (Shimadzu, Japan) coupled with a laboratorymade flame photometric detector using quartz surface-induced luminescence (QSIL-FPD), was used throughout the experiment. Butyltin compounds were based-line separated with a HP-1 fused-silica capillary column $(25 \mathrm{~m} \times$
$0.32 \mathrm{~mm} \times 0.17 \mu \mathrm{m})$. The oven temperature program conditions were $100{ }^{\circ} \mathrm{C}$ held for $1 \mathrm{~min}$, ramped at $5^{\circ} \mathrm{C} / \mathrm{min}$ to $180^{\circ} \mathrm{C}$ held for $10 \mathrm{~min}$. The temperatures of the detector and the injector were kept at $160{ }^{\circ} \mathrm{C}$ and $220^{\circ} \mathrm{C}$, respectively. High pure nitrogen severed as carrier gas and kept at the pressure of $0.26 \mathrm{MPa}$ at the column head. The flow rate of hydrogen and air were 260 and $90 \mathrm{ml} / \mathrm{min}$, respectively. A SC-1100 PC data processing system was used for data analysis.

Table 3

Summary statistics of butyltins (ng $\mathrm{Sn} / \mathrm{g}$, wet weight) in molluses from the China Bohai Sea

\begin{tabular}{|c|c|c|c|c|c|}
\hline \multirow[t]{2}{*}{ Locations } & \multirow{2}{*}{$\begin{array}{l}\text { Sampling } \\
\text { year }\end{array}$} & \multicolumn{4}{|c|}{ Concentrations: Min-Max (mean) } \\
\hline & & MBT & DBT & TBT & $\sum$ BTs \\
\hline \multirow[t]{4}{*}{ Dalian } & 2002 & $<2.8-13.8(3.4)$ & $<3.2-77.5(10.5)$ & $<2.5-108.5(40.5)$ & $10.7-120.8(54.4)$ \\
\hline & 2003 & $<2.8-21.3(8.0)$ & $<3.2-30.9(12.0)$ & $<2.5-358.0(104.5)$ & $12.4-388.4(124.5)$ \\
\hline & 2004 & $<2.8-22.3(12.5)$ & $6.4-35.0(16.9)$ & $12.1-180.7(67.2)$ & $29.0-211.6(96.6)$ \\
\hline & 2005 & $<2.8-23.6(5.2)$ & $<3.2-60.5(21.5)$ & $<2.5-50.8(13.0)$ & $0-84.6(58.9)$ \\
\hline \multirow[t]{4}{*}{ Yingkou } & 2002 & $<2.8-5.7(2.3)$ & $<3.2-10.7(12.0)$ & $<2.5-40.0(20.2)$ & $0-50.3(25.3)$ \\
\hline & 2003 & $<2.8-15.9(6.5)$ & $<3.2-20.4(11.2)$ & $<2.5-44.5(27.5)$ & $0-70.6(45.0)$ \\
\hline & 2004 & $<2.8-18.7(6.4)$ & $<3.2-22.4(10.6)$ & $7.8-35.6(22.1)$ & $21.6-58.9(39.1)$ \\
\hline & 2005 & $<2.8-9.6(3.9)$ & $<3.2-102.0(38.6)$ & $<2.5-5.6(27.5)$ & $0-132.7(25.1)$ \\
\hline \multirow[t]{4}{*}{ Jinzhou } & 2002 & $<2.8-31.7(10.2)$ & $<3.2-45.4(24.0)$ & $<2.5-82.5(33.2)$ & $0-144.4(67.4)$ \\
\hline & 2003 & $<2.8-18.3(5.4)$ & $<3.2-64.4(17.0)$ & $7.1-80.6(34.2)$ & $7.1-111.3(56.6)$ \\
\hline & 2004 & $<2.8-30.8(9.3)$ & $<3.2-29.4(13.6)$ & $8.3-71.4(25.9)$ & $8.3-105.6(48.8)$ \\
\hline & 2005 & n.a. & n.a. & n.a. & n.a. \\
\hline \multirow[t]{4}{*}{ Huludao } & 2002 & $<2.8-15.8(5.8)$ & $<3.2-32.4(14.6)$ & $5.6-88.8(31.0)$ & $14.8-108.4(51.4)$ \\
\hline & 2003 & $<2.8-45.2(7.4)$ & $<3.2-71.9(17.0)$ & $<2.5-19.3(48.2)$ & $0-238.4(72.6)$ \\
\hline & 2004 & $<2.8-17.9(8.1)$ & $<3.2-35.8(13.3)$ & $6.6-88.4(32.0)$ & $18.0-129.9(53.5)$ \\
\hline & 2005 & $<2.8-13.7(4.6)$ & $<3.2-19.2(9.5)$ & $<2.5-6.0(3.6)$ & $0-33.3(13.9)$ \\
\hline \multirow[t]{4}{*}{ Qinhuangdao } & 2002 & $<2.8-15.5(4.5)$ & $<3.2-43.9(16.9)$ & $30.8-194.6(90.1)$ & $50.5-205.5(111.4)$ \\
\hline & 2003 & $<2.8-52.2(16.7)$ & $<3.2-158.1(28.9)$ & $<2.5-185.0(39.9)$ & $0-395.3(85.5)$ \\
\hline & 2004 & $<2.8-25.8(13.5)$ & $15.3-36.5(25.5)$ & $<2.8-62.6(20.5)$ & $24.2-117.8(59.5)$ \\
\hline & 2005 & $<2.8-35.2(12.5)$ & $9.2-54.0(33.3)$ & $5.3-68.0(23.7)$ & $14.5-111.8(68.8)$ \\
\hline \multirow[t]{4}{*}{ Beidaihe } & 2002 & $<2.8-16.2(4.6)$ & $<3.2-56.9(10.8)$ & $17.7-345.6(90.8)$ & $17.7-408.3(106.1)$ \\
\hline & 2003 & $<2.8-21.1(5.2)$ & $<3.2-30.7(10.0)$ & $<2.5-383.9(71.5)$ & $3.5-397.6(86.6)$ \\
\hline & 2004 & $<2.8-24.8(10.4)$ & $<3.2-22.3(14.1)$ & $20.3-108.2(44.2)$ & $29.0-141.7(68.7)$ \\
\hline & 2005 & n.a. & n.a. & n.a. & n.a. \\
\hline \multirow[t]{4}{*}{ Tianjin } & 2002 & $<2.8-50.4(9.1)$ & $<3.2-59.0(14.0)$ & $<2.5-185.6(69.5)$ & $0-254.7(92.9)$ \\
\hline & 2003 & $<2.8-23.8(9.0)$ & $<3.2-35.4(11.5)$ & $8.6-137.3(64.1)$ & $21.8-155.3(84.6)$ \\
\hline & 2004 & $<2.8-55.3(17.8)$ & $<3.2-64.7(18.9)$ & $<2.5-135.6(44.9)$ & $15.6-219.0(81.6)$ \\
\hline & 2005 & $<2.8-7.4(4.6)$ & $6.8-22.5(17.8)$ & $<2.5-18.6(6.4)$ & $7.7-44.1(26.7)$ \\
\hline \multirow[t]{4}{*}{ Yangkou } & 2002 & $<2.8-10.5(2.2)$ & $<3.2-22.6(4.0)$ & $<2.5-45.3(19.9)$ & $0-78.4(26.1)$ \\
\hline & 2003 & $<2.8-12.0(3.7)$ & $<3.2-14.7(4.5)$ & $<2.5-20.4(10.1)$ & $0-40.3(18.3)$ \\
\hline & 2004 & $<2.8-12.3(3.4)$ & $<3.2-12.4(7.6)$ & $<2.5-35.1(14.3)$ & $0-56.9(25.3)$ \\
\hline & 2005 & $<2.8-35.8(7.5)$ & $<3.2-78.5(28.7)$ & $<2.5-68.1(12.1)$ & $0-45.6(21.5)$ \\
\hline \multirow[t]{4}{*}{ Laizhou } & 2002 & $<2.8-34.8(9.2)$ & $<3.2-33.3(12.4)$ & $7.5-47.4(30.7)$ & $17.7-128.9(52.3)$ \\
\hline & 2003 & $<2.8-33.1(6.9)$ & $<3.2-43.9(9.8)$ & $<2.5-235.6(52.5)$ & $0-239.8(69.2)$ \\
\hline & 2004 & $<2.8-25.4(7.1)$ & $<3.2-22.0(8.3)$ & $<2.5-87.6(21.9)$ & $6.3-108.5(37.4)$ \\
\hline & 2005 & n.a. & n.a. & n.a. & n.a. \\
\hline \multirow[t]{4}{*}{ Longkou } & 2002 & $<2.8-55.0(24.6)$ & $<3.2-53.7(12.3)$ & $<2.5-98.9(28.0)$ & $26.1-188.0(64.9)$ \\
\hline & 2003 & $<2.8-12.6(7.6)$ & $<3.2-24.7(12.5)$ & $<2.5-177.8(53.7)$ & $0-203.0(74.6)$ \\
\hline & 2004 & $<2.8-25.0(12.8)$ & $8.1-20.6(15.2)$ & $10.1-89.8(38.0)$ & $34.4-162.2(66.0)$ \\
\hline & 2005 & n.a. & n.a. & n.a. & n.a. \\
\hline \multirow[t]{4}{*}{ Penglai } & 2002 & $<2.8-104.8(24.7)$ & $<3.2-34.7(10.2)$ & $<2.5-181.1(33.6)$ & $0-204.4(68.5)$ \\
\hline & 2003 & $<2.8-8.6(3.7)$ & $<3.2-24.2(12.7)$ & $<2.5-97.0(38.3)$ & $0-109.8(54.7)$ \\
\hline & 2004 & $<2.8-41.3(17.3)$ & $<3.2-25.8(13.1)$ & $10.1-51.2(32.7)$ & $10.8-79.5(57.1)$ \\
\hline & 2005 & $<2.8-7.1(4.1)$ & $6.8-17.6(11.0)$ & $2.6-6.6(4.0)$ & $13.1-31.3(19.1)$ \\
\hline \multirow[t]{4}{*}{ Yantai } & 2002 & $<2.8-30.2(5.1)$ & $<3.2-20.0(6.8)$ & $<2.5-200.5(40.7)$ & $0-200.5(52.6)$ \\
\hline & 2003 & $<2.8-24.6(4.5)$ & $<3.2-40.4(14.2)$ & $<2.5-289.6(52.4)$ & $0-294.6(71.1)$ \\
\hline & 2004 & $<2.8-20.1(8.1)$ & $<3.2-20.8(12.3)$ & $8.7-76.6(27.9)$ & $8.9-97.8(48.2)$ \\
\hline & 2005 & $<2.8-19.0(5.1)$ & $<3.2-58.0(13.8)$ & $<2.5-67.8(13.7)$ & $0-144.7(28.9)$ \\
\hline \multirow[t]{4}{*}{ Weihai } & 2002 & $<2.8-52.9(9.8)$ & $<3.2-30.0(8.7)$ & $<2.5-253.4(19.8)$ & $0-259.2(78.3)$ \\
\hline & 2003 & $<2.8-25.5(5.0)$ & $<3.2-17.1(6.9)$ & $7.1-119.4(42.8)$ & $7.1-141.5(54.6)$ \\
\hline & 2004 & $<2.8-22.1(9.1)$ & $<3.2-36.4(13.0)$ & $9.6-119.4(33.0)$ & $9.6-142.7(55.2)$ \\
\hline & 2005 & $<2.8-4.9(3.1)$ & $<3.2-17.8(6.8)$ & $<2.5-19.8(4.6)$ & $0-40.1(16.6)$ \\
\hline
\end{tabular}

n.a.: no sample available. 


\subsection{Standards and reagents}

The standards including tributyltin chloride (TBT, 90\%), dibutyltin dichloride (DBT, 97\%), monobutyltin trichloride (MBT, 97\%) and tetrabutyltin (TeBT, 96\%) were purchased from Acros Organics (New Jersey, USA). TeBT was used as an internal standard. The Grignard reagent of $n$-propylmagnesium bromide $(n-\mathrm{PrMgBr}$, ca. $2.0 \mathrm{M})$ was synthesized according to the method in our laboratory (Zhou et al., 1999). All reagents used were of analytical reagent grade or better. Glassware was rinsed with de-ionized water, decontaminated overnight using 1:1 (v/v) nitric acid solution and rinsed again.

\subsection{Analytical procedure}

The analytical procedure was similar to our previous method (Zhou et al., 2001). Briefly, about 2-g sample was used to measure butyltin concentrations. After it was mixed with appropriate amount of internal standard TeBT, $10 \mathrm{ml}$ of $\mathrm{THF}-\mathrm{HCl}(11: 1, \mathrm{v} / \mathrm{v})$ solution was added and then extracted with $25 \mathrm{ml} 0.01 \%$ $(\mathrm{m} / \mathrm{v})$ tropolone-hexane solution under vigorous shaking for $40 \mathrm{~min}$. The supernatant was transferred to a flask and the residue was extracted again in the same way with another $10 \mathrm{ml}$ of hexane for $10 \mathrm{~min}$. The combined extract was concentrated to about $2-3 \mathrm{ml}$ and subjected to Grignard propylation. The analytes were purified using a chromatography column packed with anhydrous $\mathrm{Na}_{2} \mathrm{SO}_{4}(2 \mathrm{~g})$, silica gel $(2 \mathrm{~g})$ and Florisil $(2 \mathrm{~g})$ in turn from the top. The elution was conducted with $10 \mathrm{ml}$ of hexane, and the final volume was adjusted to trace level under a gentle stream of pure nitrogen.

\subsection{Quality assurance and quality control}

We analyzed certified reference materials in order to prove the validity of the method. The measured results were in good agreement with the certified values (shown in Table 2). The determination error ranged from -3 to $-8 \%$, and the relative standard derivation (RSD) values with three times repeatedly determined was less than 13\%. The detection limits (assigned 3 times signal/ noise) of TBT, DBT, MBT were 2.8, 3.2, $2.5 \mathrm{ng} \mathrm{Sn} / \mathrm{g}$ wet weight, respectively.

Quantification was performed by the internal standard method. The correlation coefficients $(r)$ of calibration curves of BTs were all higher than 0.99 . A procedural blank and a spiked sample with standards were run to check for the interference and cross-contamination with each set of eight samples, they were all free from organotin contamination or other interferences. The spiked recoveries were in the range of $84-110 \%$. These results confirmed that the proposed method was feasible in the determination of BTs in biota samples.

\subsection{Statistical analysis}

Principal component analysis (PCA) and cluster analysis were used to statistically analyze the experimental data. PCA on the analytical data was executed in order to obtain a visual representation of the main characteristics. It is a powerful way to categorize and display multivariate data in terms of samples (scores) and variables (loadings) (Meglen, 1992). When most of the variation is explained by the first two or three components, a two- or three-dimensional scattergram is enough to plot which gives essential features of the multidimensional scatter. Usually the PCs are obtained by their eigenvalues $>1$. The combined plot of scores and loadings allows us to identify groups of samples with similar behavior and the existing correlation among the original variables. Cluster analysis produces hierarchical clusters of items based on distance measures of dissimilarity or similarity. The items being clustered are usually cases from the working data file, and the distance measures are computed from their values for one or more variables. In this paper, PCA and cluster analysis were performed with SPSS 12.0 for Windows Release 12.0.0 (4 Sep. 2003, SPSS Inc.).

\section{Results and discussion}

\subsection{Concentrations of butyltins}

Table 3 summarized the concentration ranges and their mean values of butylin compounds in different sampling sites and sampling year. The concentration of TBT ranged from $<2.5$ to $345.6 \mathrm{ng} \mathrm{Sn} / \mathrm{g}$ (Beidaihe, Mer) for 2002, $<2.5$ to $358 \mathrm{ng} \mathrm{Sn} / \mathrm{g}$ (Dalian, Chl) for 2003, <2.5 to $158.4 \mathrm{ng}$ $\mathrm{Sn} / \mathrm{g}$ (Dalian, Chl) for 2004, $<2.5$ to $68.1 \mathrm{ng} \mathrm{Sn} / \mathrm{g}$ (Yangkou, Chl) for 2005 , respectively. The concentration of DBT ranged from $<2.8$ to $77.5 \mathrm{ng} \mathrm{Sn} / \mathrm{g}$ (Dalian, Sca) for $2002,<2.8$ to $158.1 \mathrm{ng} \mathrm{Sn} / \mathrm{g}$ (Qinhuangdao, Rud) for 2003, $<2.8$ to $64.7 \mathrm{ng} \mathrm{Sn} / \mathrm{g}$ (Tianjin, Mer) for

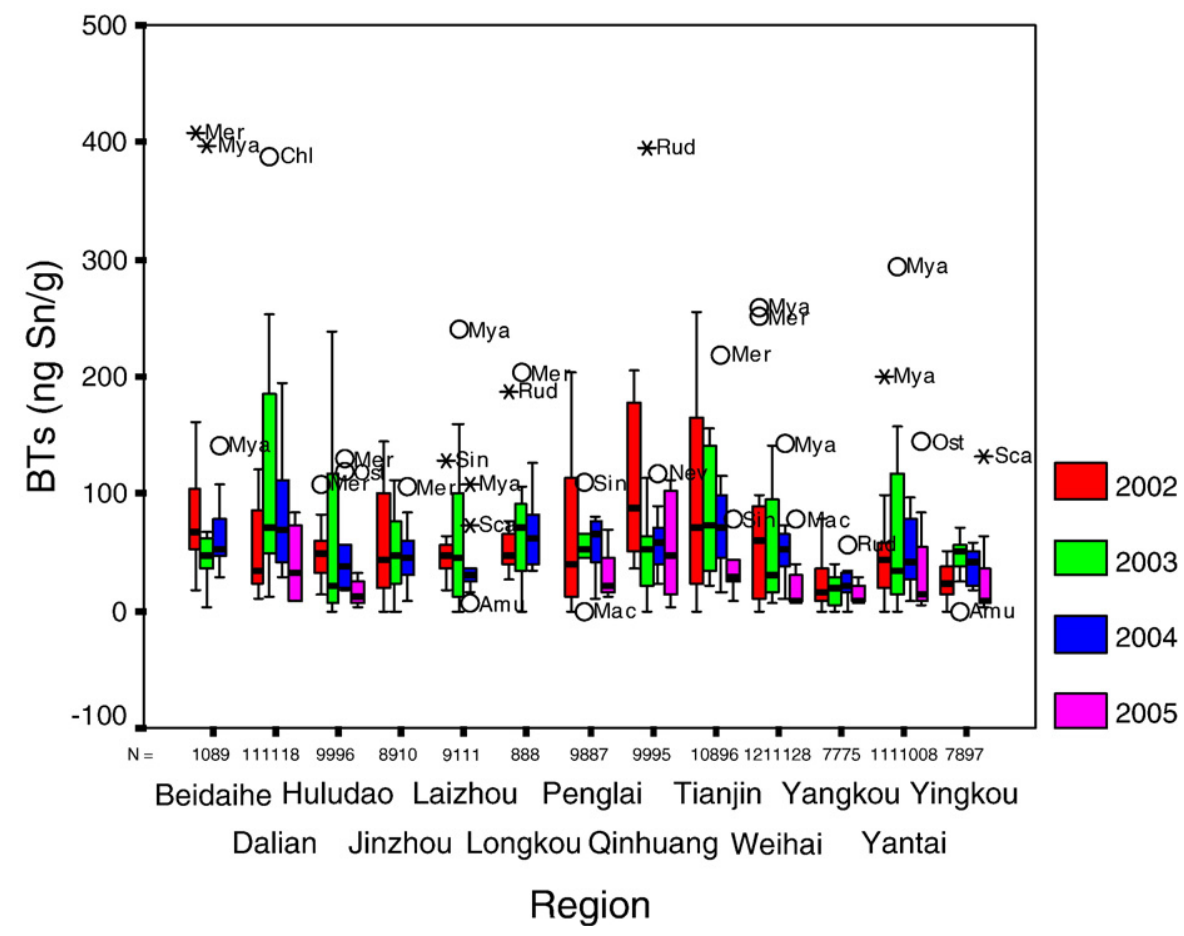

Fig. 2. Box-and-whisker plots for $\Sigma$ BTs of the four sampling in molluscs ( $N$ represents sample number, only sample number $>5$ was used in statistical analysis). 
Table 4

One-Way ANOVA for the concentrations of BTs in molluscs in four years

\begin{tabular}{lllllll}
\hline & $P$ & \multicolumn{7}{l}{} \\
\cline { 2 - 7 } & 2002 vs & 2002 vs & 2002 vs & 2003 vs & 2003 vs & 2004 vs \\
& 2003 & 2004 & 2005 & 2004 & 2005 & 2005 \\
\hline MBT & 0.375 & 0.692 & 0.230 & $\mathbf{0 . 0 4 0}$ & 0.398 & $\mathbf{0 . 0 2 0}$ \\
DBT & 0.486 & 0.185 & 0.028 & 0.610 & 0.093 & 0.141 \\
TBT & 0.901 & 0.133 & $\mathbf{0 . 0 0 1}$ & 0.092 & $\mathbf{0 . 0 0 1}$ & $\mathbf{0 . 0 0 0}$ \\
$\Sigma$ BTs & 0.954 & 0.374 & $\mathbf{0 . 0 1 2}$ & 0.338 & $\mathbf{0 . 0 1 1}$ & $\mathbf{0 . 0 1 8}$ \\
\hline
\end{tabular}

Bold: significant difference at the 0.05 level.

$2004,<2.8$ to $102 \mathrm{ng} \mathrm{Sn} / \mathrm{g}$ (Yingkou, Sca) for 2005, respectively. The concentration of MBT ranged from $<3.2$ to $104.8 \mathrm{ng} \mathrm{Sn} / \mathrm{g}$ (Penglai, Rap) for 2002, $<3.2$ to $52.2 \mathrm{ng} \mathrm{Sn} / \mathrm{g}$ (Qinhuangdao, Rud) for 2003, $<3.2$ to $55.3 \mathrm{ng} \mathrm{Sn} / \mathrm{g}$ (Tianjin, Nev) for $2004,<3.2$ to $35.8 \mathrm{ng} \mathrm{Sn} / \mathrm{g}$ (Yangkou, Chl) for 2005, respectively. The total of BTs ranged from below the detection limit to $408.3 \mathrm{ng} \mathrm{Sn} / \mathrm{g}$ with a mean value of $54.5 \mathrm{ng} \mathrm{Sn} / \mathrm{g}$ during the investigated four years. Amongst BTs, TBT is the dominant compound accounting for $0 \%$ to $100 \%$ (mean $58.5 \%$ ), BDI suggesting the recent input of TBT in most of Bohai coastal sites.
Another survey on the BTs contamination in seafood from selected cites along Bohai Sea by Zhou et al. (2001) revealed that the TBT ranged from $<6.9$ to $17,175 \mathrm{ng} \mathrm{Sn} / \mathrm{g}$ on wet weight basis and Dalian was the most seriously polluted area by TBT. When compared the present results with other coastal sites worldwide, it was found that BTs levels in Bohai coast are similar to those in developing Asian countries such as Korea (Hong et al., 2002), Philippines (Prudente, 1999) and Thailand (Kan-atireklap et al., 1998), but higher than those in some TBT antifouling paints-banned countries such as USA (Uhler et al., 1993), Austria (Hong et al., 2002), Canada (Chau et al., 1997) and Japan (Harino et al., 1998). So the BTs contamination in Bohai Sea is rather severe and urgent control or management should be reacted as soon as possible.

\subsection{Spatial distribution and temporal trends}

The temporal trends for $\Sigma \mathrm{B} T$ s in molluses during the four sampling year was statistically analyzed as box-and-whisker plots (Fig. 2). In the layout, the box encloses the middle half of the data. The horizontal line in the box represents the median, the low and upper edges of the box denote the 25 th and 75 th percentiles. Singular values are marked by "O", which a

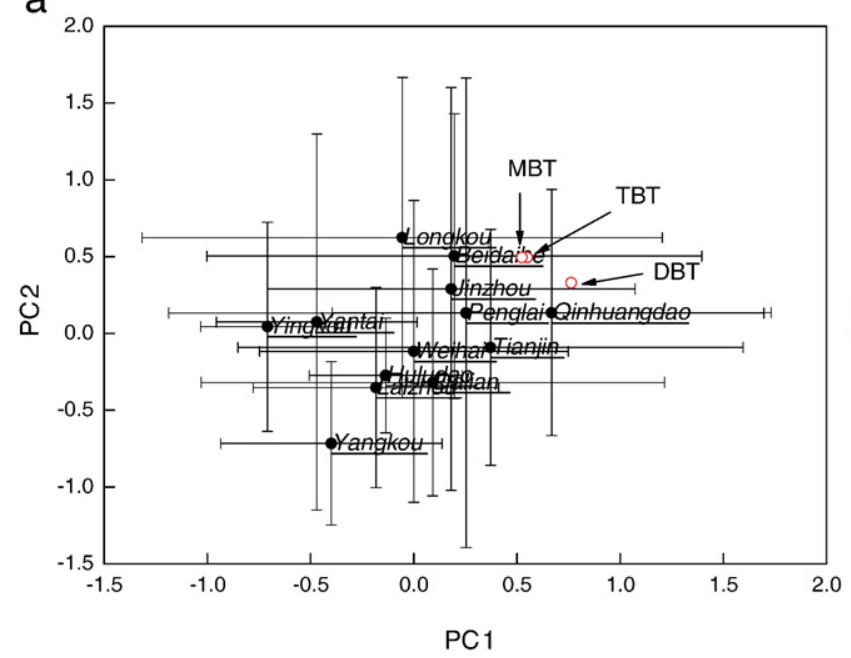

C

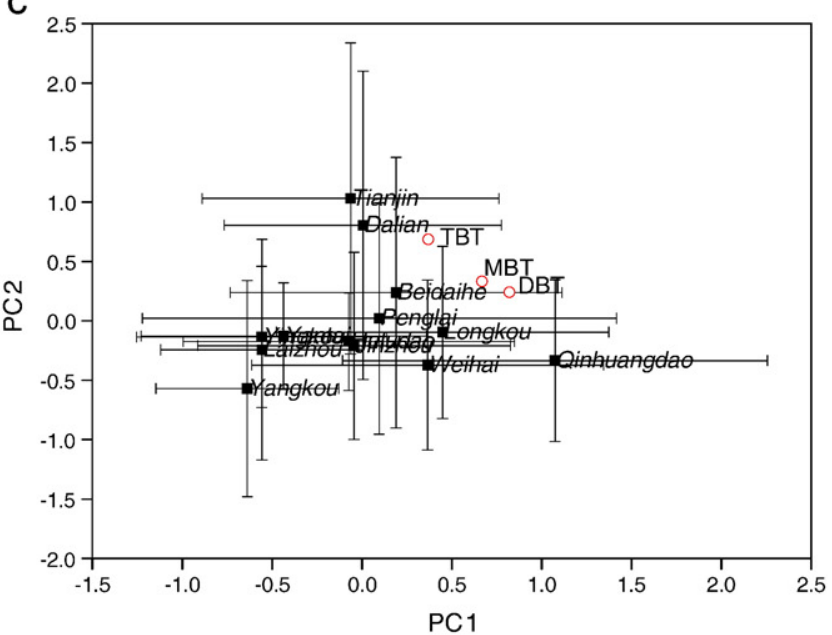

b

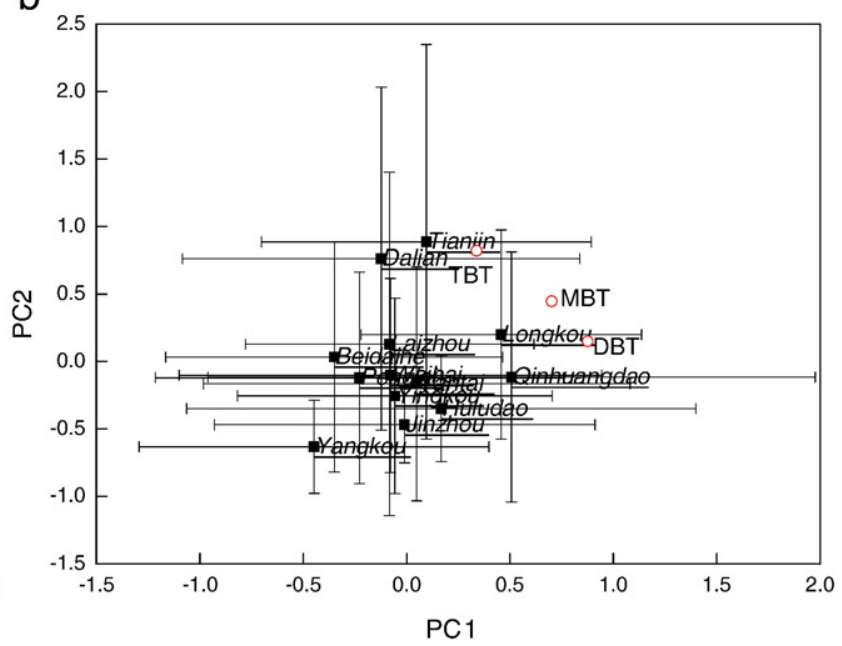

d

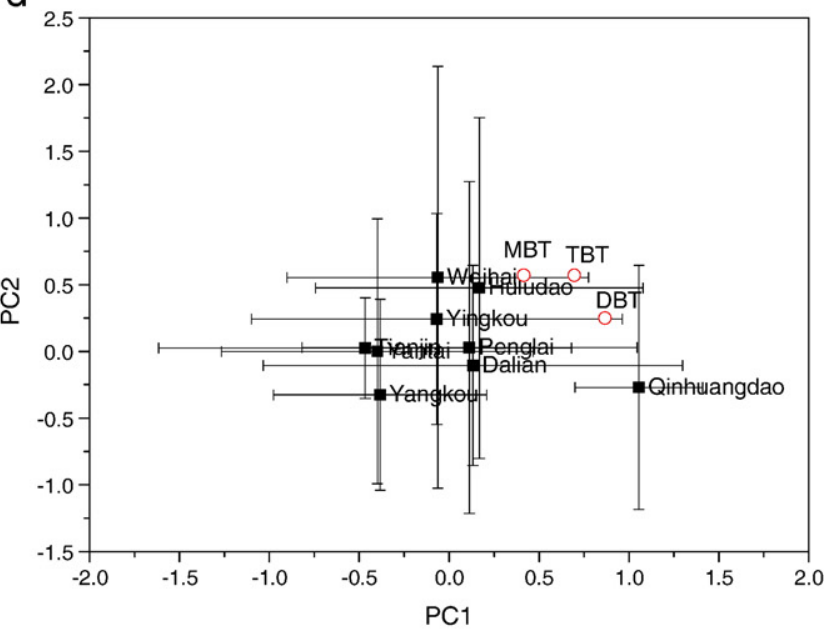

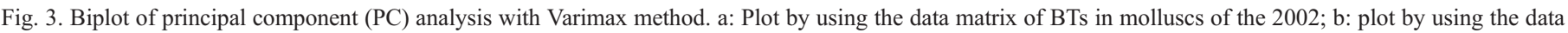

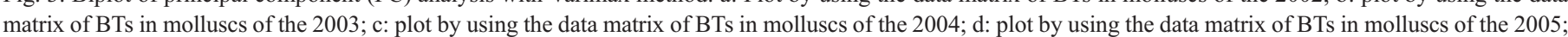

“口”: sample sites; "○”: butyltin compounds. 
are beyond the 150 percentiles of the difference between 25 th and 75 th percentiles. Extremum values are marked by “*”, which are beyond the triplication of the difference between 25 th and 75 th percentiles.

In this visual presentation, we could see that the concentration of ¿BTs varied greatly among sampling sites. As a whole, relatively high residue levels of $\Sigma$ BTs in samples were found in Dalian, Qinhuangdao, and Tianjin, while low concentrations were found in samples from Yangkou and Yingkou. Although the concentration ranges varied with different sampling year, the median concentration of $\Sigma$ BTs in the most sampling sites was not significantly changed during the sampling years, except $\Sigma$ BTs in samples from several sites decreased in 2005.

In addition, a statistical method One-Way ANOVA was used to compare the variations of BTs concentrations in the four years (Table 4). A value of $P<0.05$ was considered to indicate a significant difference between two sets of data. The results showed that the concentrations of $\Sigma \mathrm{BT}$, and also concentrations of TBT in 2005 were significantly different with the other three years, which indicate the consistent trends for $\Sigma$ BTs as the above box-and-whisker analysis. The decline of $\Sigma$ BTs may be caused by the reduction of TBT release. Also, the concentrations of the metabolites MBT was significantly varied in 2003 vs 2004, and 2004 vs 2005 .

\subsection{The results of principal component analysis}

PCA was performed to analyze the relationships of the four batches of data (Fig. 3, a-d). Fig. 3a represents the first sampling of loading and scores plots. PC1 of Fig. 3 a accounted for $60.65 \%$ of the total variance and PC2 accounted for $27.30 \%$. In the plot of Fig. $3 \mathrm{a}$, we could see that Longkou and Beidaihe were highly contaminated by TBT and MBT. Qinhuangdao had high concentration of DBT, while the levels of BTs were not so high in Yangkou and Yingkou. Fig. $3 \mathrm{~b}$ was the PCA result of 2003 , and PC1 and PC2 accounted for $66.38 \%$ and $22.44 \%$ of the total variance, respectively. This figure showed that Dalian and Tianjin were highly polluted by TBT; Longkou and Qinhuangdao were abundantly contaminated by DBT and MBT. The other sampling sites were not so seriously contaminated by BTs, and the Yangkou and Yingkou also showed the lowest levels. The result of 2004 was similar to 2003, which showed that in this period, there was little change of the contamination of BTs along the Chinese Bohai coast. The result of 2005 indicated that the contamination of TBT in Dalian and Tianjin was not so serious compared with the previous two years, but similar result was obtained in Qinhuangdao and Yangkou. On the whole, Dalian, Tianjin and Longkou, in this period, the concentrations of TBT were relatively high. These sites are important seaports of China with extremely high density of various ships and boats. TBT resulting from the release of antifouling paints applied on the vessels due to the intensive maritime activities might account for the currently high BTs contents in these mollusc samples. So, it was reasonable that we found in the areas of Yangkou and Yingkou with less vessel activities, relatively low BTs levels. However, it should be noted that the samples from Yingkou, a fishery area, were also contaminated by BTs. We investigated that TBT-based coatings on the marine aquaculture facilities such as fishnet and sea pens might be one of the sources for BTs in the cultured area. DBT and MBT mainly come from the degradation of TBT in coastal waters. Therefore, the high concentration of DBT in molluscs from Qinhuangdao indicated that TBT degradation might be important at this area. Butylins Degradation Index (BDI) could be used to evaluate the quantitative importance of TBT degradation (Díaz et al., 2007). Values of BDI $<1$ indicated a "recent" TBT contamination. The calculated BDI $(\mathrm{BDI}=[(\mathrm{MBT}+\mathrm{DBT}) / \mathrm{TBT}]$, where, MBT, DBT and TBT refer to their total concentrations) in Qinhuangdao averaged 1.3, suggesting relatively "aged" contamination of BTs. However, possible other additional sources of DBT such as leaching from PVC or discharges from industrial in this location could not be ruled out at present, further study needed to confirm this presume.

\subsection{Bioaccumulation potential}

Based on the investigation by Jiang et al. (2001), the TBT in waters from selected shipyard and seaport along Bohai Sea ranged from 18.8 to $322.4 \mathrm{ng} \mathrm{Sn} / 1$ and sometimes higher than the toxicity threshold of the aquatic organisms. Mollusc can bioaccumulate these contaminants from ambient water. The bioaccumulation factor (BCF) of BTs is as high as 1000 or more by rough estimate according to the current average concentration. However, the accumulated concentrations in a

\section{Dendrogram using Average Linkage (Between Groups)}

\section{Rescaled Distance Cluster Combine}

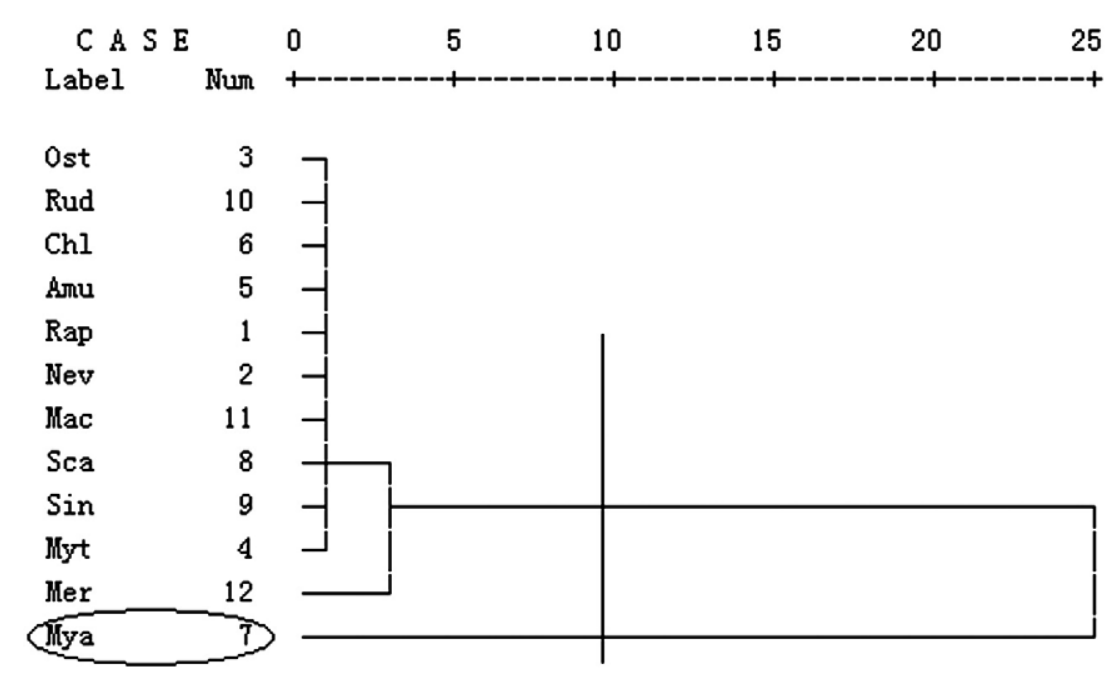

Fig. 4. Dendrogram derived from the hierarchical cluster analysis (plot by using the data matrix of $\Sigma$ BTs in samples of the 2002). 
specific species varied quite differently. Determination of BTs in various species can provide helpful information in selecting sensitive indicators for pollution monitoring.

Noticeably, ¿BTs in clam Mya arenaria (Mya) were repeatedly found in the form of singular or maximum values (Fig. 2). Take the data matrix of the 2002 as example, classification by cluster analysis also suggested that Mya is much different from other species (Fig. 4). Similar results can be found in the subsequent sampling years. The accumulate ability of Mya was also confirmed in our laboratory exposure conditions (Yang et al., 2006). Meretix meretrix (Mer) and Scapharca subcrenata (Sca) may be other suggested organisms to study their accumulation behavior for potential biomonitor in the future, because the BTs concentrations in Mer and Sca are also quite different with other detected species. Although the snails Rap and Nev are predator, however, the trophic biomagnification of BTs through the food chain was not observed. The accumulation of pollutants by an organism might be complicated, which can be affected by various biotic and abiotic factors (Looster et al., 2000).

\section{Conclusion}

The continuous monitoring indicated the severe and wide contamination of BTs along Chinese Bohai coast. High percentage of TBT among BTs indicated recent TBT pollution sources in these sites. PCA was performed to investigate the relationships between the concentration of BTs and sampling sites. The high BTs levels were associated with the vessel activities. Bioaccumulation of BTs varied strongly among species. The present monitoring work provides a baseline data to valuate the contamination status of BTs in China Bohai Sea, and, hopefully, to promote establishing the related measure.

\section{Acknowledgements}

This work was jointly supported by the National Basic Research Program of China (2003CB415001), and the National Natural Science Foundation of China (40503014, 40601101). We greatly appreciate Professor F. C. Adams for his kind offering of CRM 477.

\section{References}

Champ MA. A review of organotin regulatory strategies, pending actions, related costs and benefits. Sci Total Environ 2000;258:21-71.

Chau YK, Maguire RJ, Brown M Yang F, Batchelor SP, Thompson JAJ. Occurrence of butyltin compounds in mussels in Canada. Appl Organometal Chem 1997;11:903-12.

Díaz J, Higuera-Ruiz R, Elorza J, Irabien A, Ortiz I. Distribution of butyltin and derivatives in oyster shells and trapped sediments of two estuaries in Cantabria (Northern Spain). Chemosphere 2007;67:623-9.

Fent K. Ecotoxicology of organotin compounds. Crit Rev Toxicol 1996;26: $1-117$.

Harino H, Fukusima M, Yamamoto Y, Kawai K, Miyazaki N. Contamination of butyltin and phenyltin compounds in the marine environment of Otsuchi Bay, Japan. Environ Pollut 1998;101:209-14.
Hong HK, Takahashi S, Min BY, Tanabe S. Butyltin residues in blue mussels (Mytilus edulis) and arkshells (Scapharca broughtonii) collected from Korean coastal waters. Environ Pollut 2002;117:475-86.

Jiang GB, Zhou QF, Liu JY, Wu DJ. Occurrence of butyltin compounds in the waters of selected lakes, rivers and coastal environments from China. Environ Pollut 2001;115:81-7.

Kan-atireklap S, Yen NTH, Tanabe S, Subramanian AN. Butyltin compounds and organochlorine residues in green mussel (Perna viridis L.) from India. Toxicol Environ Chem 1998;67:409-24.

Konstantinou IK, Albanis TA. Worldwide occurrence and effects of antifouling paints booster biocides in the aquatic environment: a review. Environ Inter 2004;30:235-48.

Laughlin RB, French W, Guard HE. Accumulation of bis (tributyltin) oxide by the marine mussels Mytilus edulis. Environ Sci Technol 1986;20:884-90.

Looster PW, Fent K, Berg M, Goudsmit G, Schwarzenbach R. Uptake and elimination of triorganotin compounds by larval midge Chironomus riparius in the absence and presence of Aldrich humic acid. Environ Sci Technol 2000;34:5165-71.

Meglen RR. Examining large database: a chemometric approach using principal component analysis. Mar Chem 1992;58:329-41.

Michael B. Imposex and tributyltin contamination as a consequence of the establishment of a marina, and increasing yachting activities at Phuket Island, Thailand. Environ Pollut 2002;117:421-9.

Midorikawa S, Arai T, Harino H, Ohji M, Cu ND, Miyazaki N. Concentrations of organotin compounds in sediments and clams collected from coastal areas in Vietnam. Environ Pollut 2004;131:401-8.

Morcillo Y, Porte C. Monitoring of organotin compounds and their effects in marine molluscs. TrAC 1998;17:109-17.

Prudente MS. Heavy metals, organochlorines and butyltins contamination in the Philippine environment. Ph.D Thesis, EhimeUniversity, Japan; 1999.

Rainbow PS. Biomonitoring of heavy metal availability in the marine environment Mar Pollut Bull 1995;31:183-92.

Rüdel H, Lepper P, Steinhanses J. Retrospective monitoring of organotin compounds in marine biota from 1985 to 1999: results from the German Environmental Specimen Bank. Environ Sci Technol 2003;37:1731-8.

Salánki J, Farkas A, Kamardina T, Rózsa KS. Molluscs in biological monitoring of water quality. Toxicol Lett 2003;140-141:403-10.

Sidharthan M, Young KS, Woul LH, Soon PK, Shin HW. TBT toxicity on the marine microalga Nannochloropsis oculata. Mar Pollut Bull 2002;45: $177-80$.

Shim WJ, Hong SH, Kim NS, Yim UH, Li DH, Oh JR. Assessment of butyl- and phenyltin pollution in the coastal environment of Korea using mussels and oysters. Mar Pollut Bull 2005;51:922-31.

Tong SL, Pang FY, Phang SM, Mandlai HC. Tributyltin distribution in the coastal environment of peninsular Malaysia. Environ Pollut 1996;91:209-16.

Uhler AD, Durell GS, Steinhauer WG, Spellacy AM. Tributyltin levels in bivalve mollusks from the east and west coasts of the United States: results from the 1988-1990 national status and trends mussel watch project. Environ Toxicol Chem 1993;12:139-53.

Yang RQ, Zhou QF, Jiang GB. Butyltin accumulation in marine clam Mya arenaria: an evaluation of its suitability for monitoring butyltin pollution. Chemosphere 2006;63:1-8.

Zhao RY, Cheng JM, Zhao DD. Marine mollusca fauna of Dalian. Beijing: Oceanic Press; 1982.

Zhou QF, Jiang GB, Qi DQ. Synthesis and application of propylmagnesium bromide Grignard reagent in derivation of butyltin compounds. Chinese J Anal Chem 1999;27:1197-9.

Zhou QF, Jiang GB, Liu JY. Small-scale survey on the contamination status of butyltin compounds in seafood collected from seven Chinese cities. J Agricul Food Chem 2001;49:4287-91. 